\title{
Dioxygen Activation by a Low-Valent Cobalt Complex \\ Employing a Flexible Tripodal N-Heterocyclic Carbene Ligand
}

\section{Supporting Information}

Xile Hu, Ingrid Castro-Rodriguez, and Karsten Meyer*

Department of Chemistry and Biochemistry, Mail Code 0358, University of California, San Diego, 9500 Gilman Drive, La Jolla, California 92093-0358 (USA)

E-mail: kmeyer@ucsd.edu 
Crystallographic details for a crystal containing a mixture of [(TIMEN $\left.\left.{ }^{\mathrm{Xyl}}\right) \mathrm{Co}\right] \mathrm{Cl}$ and [(TIMEN $\left.\left.{ }^{\mathrm{Xyl}}\right) \mathrm{CoCl}\right] \mathrm{Cl} \cdot \mathbf{2} \mathrm{CH}_{3} \mathrm{CN}\left(\mathbf{1 m i x} \cdot \mathbf{2} \mathrm{CH}_{3} \mathrm{CN}\right)$ : Red crystals were grown by diffusion of ether into an acetonitrile solution of 1 . A crystal of dimensions $0.4 \times 0.2 \times$ $0.1 \mathrm{~mm}^{3}$ was mounted on a glass fiber. A total of 11483 reflections $(-13 \leq h \leq 13,-13 \leq k$ $\leq 13,-27 \leq l \leq 26)$ were collected at $T=100(2) \mathrm{K}$ in the range of 0.97 to $22.5^{\circ}$ of which 5263 were unique $\left(R_{\text {int }}=0.0223\right) ; \mathrm{Mo}_{\mathrm{K} \alpha}$ radiation $(\lambda=0.71073 \AA)$. The structure was solved by direct methods (Shelxtl Version 6.10, Bruker AXS, Inc., 2000). The structure was modeled with a $42 \%$ of $\left[\left(\mathrm{TIMEN}^{\mathrm{Xyl}}\right) \mathrm{Co}\right] \mathrm{Cl}$ and $58 \%$ of $\left[\left(\mathrm{TIMEN}^{\mathrm{Xyl}}\right) \mathrm{CoCl}\right] \mathrm{Cl}$ with two co-crystallizing acetonitrile solvent molecules. All non-hydrogen atoms were refined anisotropically. Hydrogen atoms were placed in calculated idealized positions. The residual peak and hole of electron densities were 1.060 and $-0.483 \mathrm{eA}^{-3}$. The absorption coefficient was $0.563 \mathrm{~mm}^{-1}$. The least squares refinement converged with residuals of $R(F)=0.1112, w R\left(F^{2}\right)=0.2599$ and a $\mathrm{GOF}=1.252(I>2 \sigma(I)) . \mathrm{C}_{43} \mathrm{H}_{51} \mathrm{Cl}_{1.58} \mathrm{CoN}_{9}$, space group P-1, Triclinic, $a=10.6509(19), b=10.6886(19), c=20.955(2), \alpha=93.521(3)^{\circ}, \beta$ $=93.052(3)^{\circ}, \gamma=119.836(2)^{\circ}, V=2055.8(6) \mathrm{A}^{3}, Z=2, \rho_{\text {calcd }}=1.307 \mathrm{Mg} / \mathrm{m}^{3}$. 
Figure S1. Solid-sate molecular structure of $1 \mathrm{mix} \cdot \mathbf{2 C H}_{3} \mathbf{C N}$. Hydrogen atoms and solvent molecules are omitted for clarity, thermal ellipsoids at 50\% probability. Selected bond lengths $(\AA)$ : $\operatorname{Co}(1)-C(3) 2.038(9), \operatorname{Co}(1)-C(16)$ 1.922(10), $\operatorname{Co}(1)-C(29) 2.040(10)$, Co(1)-N(1) 2.360(10), $\quad \mathrm{Co}(2)-\mathrm{C}(3) \quad 2.059(9), \quad \mathrm{Co}(2)-\mathrm{C}(16) \quad 2.088(10), \quad \mathrm{Co}(2)-\mathrm{C}(29)$ 2.071(9), $\mathrm{Co}(2)-\mathrm{Cl}(1) 2.272(5)$.

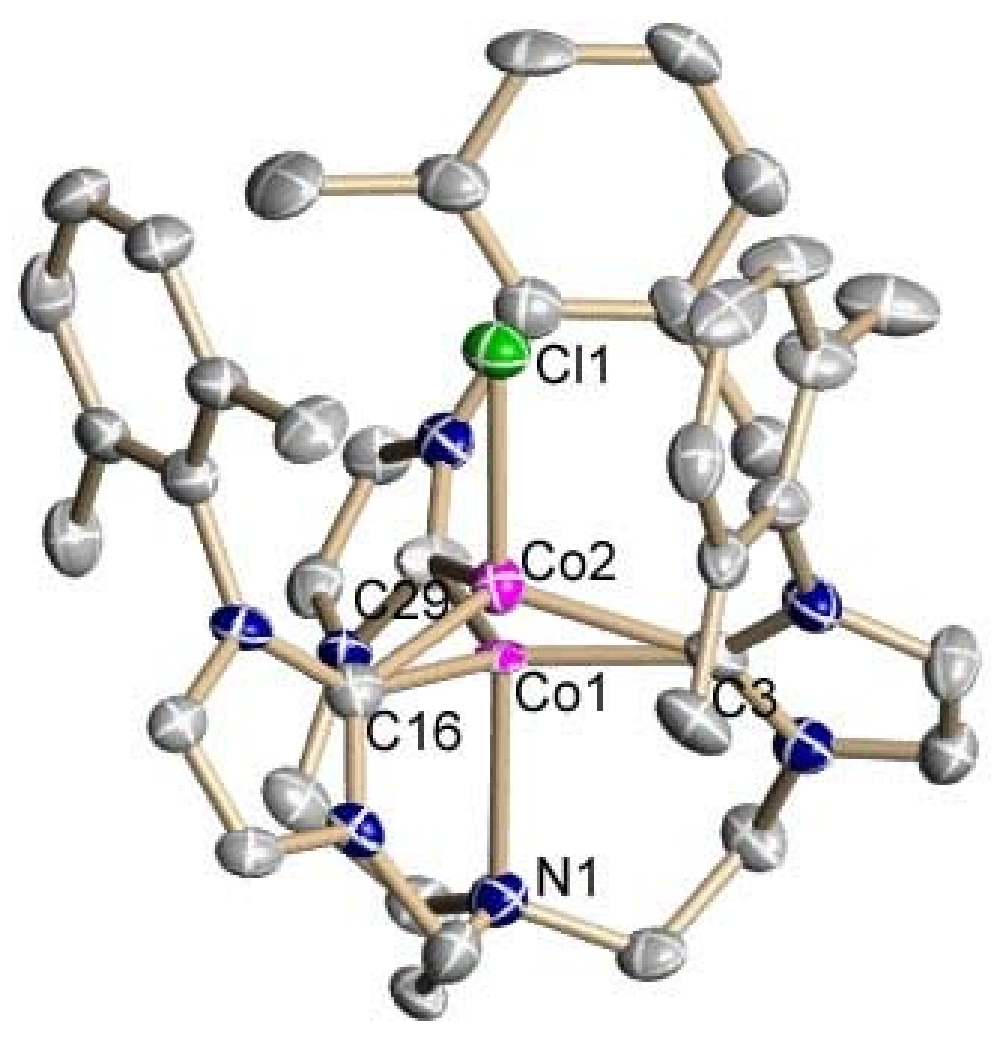


Figure S2. Co-crystallization of $\mathbf{1}$ (left) and $\mathbf{3}$ (right) in $\mathbf{1} \mathbf{m i x} \cdot \mathbf{2} \mathbf{C H}_{3} \mathbf{C N}$ (middle). Hydrogen atoms, counter ions, and solvent molecules are omitted for clarity, thermal ellipsoids at $50 \%$ probability.
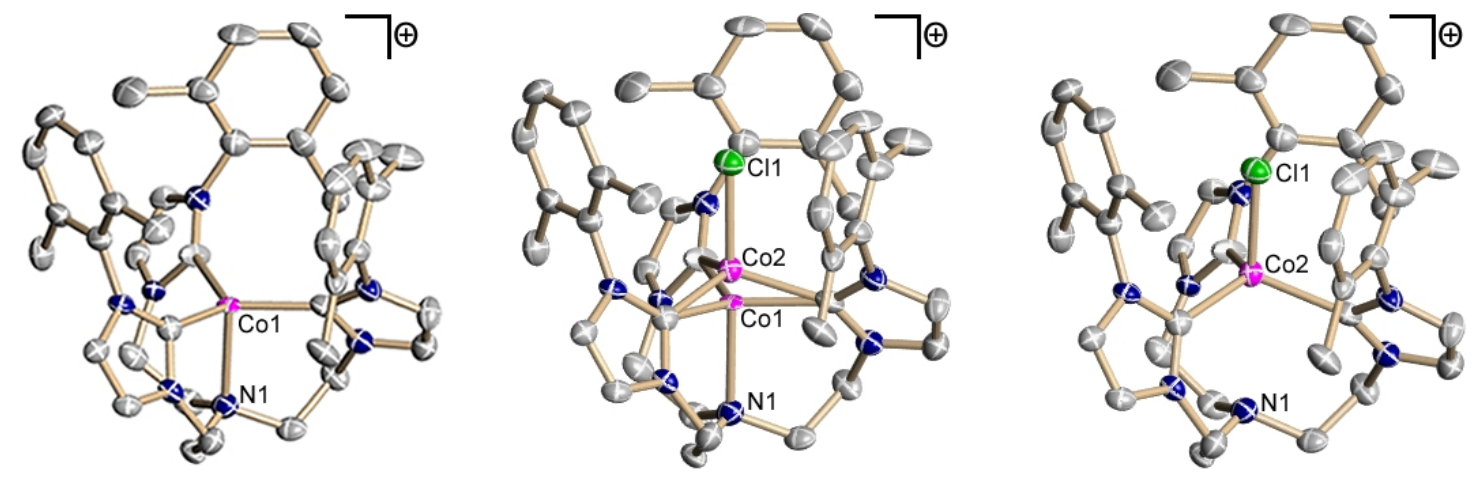
Figure S3. UV-Vis Spectrum of complex 5 recorded in DMSO solution.

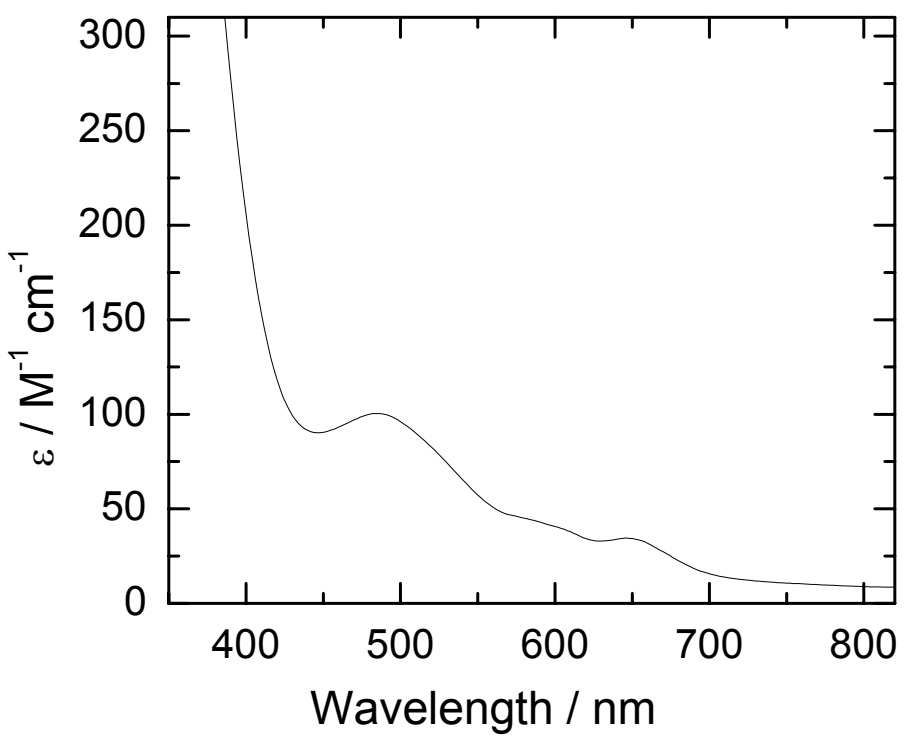

